\title{
Labeling of ethnic food in the Prato Chinese community
}

\author{
A. Guidi • A. Armani - L. Castigliego • X. N. Li • \\ F. Fanzone $\cdot$ S. Fusco $\cdot$ E. Facibeni $\cdot$ D. Gianfaldoni
}

Published online: 1 May 2010

(C) Springer Science+Business Media B.V. 2010

\begin{abstract}
Ethnic food consumption is a quickly growing reality within Chinese communities, which have a well-organized "internal" food market for both Asian and ethnic foods produced in the European Union. The main problems associated with these markets are related to hygienic conditions, certifications of accomplishment, and personnel management. Moreover, controls and identification of the products are difficult because of cultural and linguistic barriers. In this study, five markets managed by the Chinese were visited, and the conformity of the reported label information found on different kinds of food (prepackaged or loose) was assessed by a collaboration between the Local Authorities of Control of the Prato territory, which hosts the largest Chinese community in Italy, and of native speakers of Chinese. All visited markets presented products $(n=75)$ with non-conformities: lack of translation (6\%) and incomplete/mistaken translation of the commercial name $(72 \%)$ and place of production (12\%). In addition to the legal implications of the observed noncompliances, certain sanitary issues were taken into consideration. In fact, a number of the products that belong to risk categories could be misclassified in a non-risk category. Lastly, missing ingredients or complete alteration of their commercial names may represent health threats in cases of allergen ingestion by allergic or intolerant consumers.
\end{abstract}

Keywords Labeling $\cdot$ Ethnic food · Food safety

\section{Introduction}

Ethnic food is becoming a business of increasing importance in the form of delivery and catering. In particular, catering is influenced by mere food trends, which have caused a

\footnotetext{
A. Guidi $(\bowtie) \cdot$ A. Armani $\cdot$ L. Castigliego $\cdot$ X. N. Li $\cdot$ D. Gianfaldoni

Dipartimento di Patologia Animale, Profilassi ed Igiene degli Alimenti, Università di Pisa, Pisa, Italy e-mail: aguidi@vet.unipi.it

F. Fanzone $\cdot$ S. Fusco $\cdot$ E. Facibeni

U.O. Igiene degli Alimenti e della Nutrizione, Prato, Italy
} 
noticeable proliferation of ethnic restaurants from the Chinese, the pioneers of "poor" ethnic food, to the more sophisticated Japanese, who have imposed a real chic-food fashion.

In Italy, this market, even though it is quickly growing, is not yet consolidated, especially in comparison to countries such as France, Germany, and England, where this sector is run with an astonishing rate, and makes ethnic-food a product d'elite. One exception can be found within Chinese communities that have "internal" food markets, which are well activated and organised. At present, those markets commercialise both Asian and ethnic foods coming from the European Union or products that are sometimes made in Italy in because importation from the original countries has been banned. However, despite a very good commercial organisation, such a market has always been characterised by problems related to hygiene conditions, certification accomplishments, self-rule (autocontrol), and personnel management. Moreover, many products entail problems with control and identification, because of the difficulties in obtaining information that is often incomplete (Guidi and Gianfaldoni 2008). Such concerns are made still more critical by the cultural and linguistic differences, which set barriers between the Chinese operators and the official inspectors who do not succeed in properly "penetrating" such communities. These factors imply the need for greater use of repressive counteractions, which in this context, turn out to be the only system to contrast the irregularities.

In this study, carried out together with the Local Authorities of Control, nonconformities of labeling are reported that have been found within Chinese shops that were checked as part of a wider project of control. The data presented here are intended to support a formative and informative program geared towards the employees of the food sector within the AUSL of the Prato territory which hosts the biggest Chinese community in Italy. Such a project, with the aim to overcome the linguistic barriers and have a bigger impact on the Chinese operators, profited from the collaboration of technicians from the People's Republic of China who have been fundamental to this investigation.

\section{Materials and methods}

Five markets managed by Chinese people were visited. The markets were a combination of supermarkets and little shops that sold products related to meat, fish, and gastronomy. During the visits, the conformity of the reported information on the labels was verified on all of the food products of animal origin and non-packaged, pre-packaged, and exposed food items. This was done with the aid of a native-Chinese speaking collaborator who was able to verify the correspondence of the translation. The non-conforming food products were purchased and recorded.

\section{Results}

All the visited shops presented products with labeling non-conformities. Specifically, 75 products were identified that had non-conformities. Six percent showed a lack of translation. Others had incomplete or mistaken translations relating to commercial denomination $(72 \%)$ or place of production $(12 \%)$. The following are examples of mistaken translations: "potatoes snack" in place of "dried fish of different origin," "duck tongues" and "soy marmalade" in place of "bovine meat source," "jujune" in place of "snails", "palm cores" in place of "jellyfish," and "canned beans" in place of "canned fish products." 


\section{Discussion}

Labeling has always been a crucial element in the framework of food commercialisation. In fact, labels represent the "ID card" of the products so that rather than relying on communication with the operator that put the product on the market, the consumer can read the product characteristics. Furthermore, labeling represents one of the main mediums for the correct management of traceability, with regard to the hold information. This will enable the control of potential risks for consumer health on each level of food commercialisation. Eventually, this will also establish reclamation of those products that represent an unexpected risk as required by EU Regulation No. 178/2002.

Unfortunately, the labeling of ethnic products often implies difficulties in both the application and the controls mainly due to the linguistic differences. In fact, according to the law currently in force, it is compulsory that the requested information be present in the Italian language. This specification is anything but banal, especially in light of the several mistaken or incomplete translations that have been found that are not in accordance with Italian Legislative Decrees No. 109/1992, 181/2003. Such labeling incongruence is sometime due to mere negligence. However, it can also be due to an aforethought modification of the reported information with the aim of circumventing the normative related to the importation. The case of the duck tongues found in some markets with the denomination of "potatoes snack" is an example of aforethought modification to allow for entrance into the EU.

Besides the legal implications of the observed non-compliances, this work gives stimulation for reflection on the possible sanitary implications for the consumers. Indeed such products could belong to risk categories, but could also escape certain types of controls because they were wrongly classified. Moreover, the missing declaration of some ingredients or the complete substitution of the commercial denomination of a product, such as "potatoes snack" in place of "dehydrated fish" or "jujube" in place of "snails," is extremely dangerous if the foods are ingested by allergic or intolerant consumers. This concern is continuously growing and has recently resulted in the creation of a normative, Italian Legislative Decree No. 114/2006, which established an obligation to clearly indicate on the labels every ingredient belonging to the list of potential allergens or derivatives. Therefore, it is clear that labeling control of ethnic products requires a more accurate investigation with respect to the standard controls. These efforts would profit from interpreters for the verification of translation correctness. Ethnic products are increasingly common on our markets. In 2007, ethnic food consumption increased noticeably together with the exclusive products (Barzaghi 2007). As a consequence of the recent economic recession, there has not been a market contraction of the discussed products and their consumption is augmented so much that some of these products are appearing in district markets (Altomare 2008).

\section{References}

Altomare G (2008) I furbi nel piatto. http://ilmondoggi.splinder.com/tag/quello+che+mangiamo Barzaghi D (2007) Un carrello pieno di "lusso.” Il sole 24ore. http://www.isae.it/rs_07092007.pdf

Commission Regulation (EC) No. 178/2002 laying down the general principles and requirements of food law, establishing the European Food Safety Authority and laying down procedures in matters of food safety

Guidi A, Gianfaldoni D (2008) What kind of formation in the multiethnic culture of the European Union of the third millennium? Vet. Res. Comm. 32:355-357 
Italian Legislative Decree No. 109 implementing EEC Directives 89/395/CEE and 89/396/CEE concerning the labelling, packaging and advertising of foodstuffs of 27 January 1992

Italian Legislative Decree No. 181 implementing Directive 2000/13/EC concerning the labelling, presentation and advertising of foodstuffs of 23 June 2003

Italian Legislative Decree No. 114 of 8 February 2006 implementing Directives 2003/89/EC, 2004/77/EC and 2005/63/EC as regards indication of the ingredients present in foodstuffs of 23 March 2006 